\title{
PARAMETRIC STUDY ON AN INDUSTRIAL STRUCTURE FOR VARIOUS DYNAMIC LOADS
}

\author{
S.Ramesh ${ }^{1}$, V. Vinoth Kumar ${ }^{2}$ \\ ${ }^{1}$ M.Tech Student, Department of Civil Engineering, Prist University, Kumbakonam Campus, Tamilnadu, India \\ ${ }^{2}$ Asst. Professor, Department of Civil Engineering, Prist University, Kumbakonam Campus, Tamilnadu, India
}

\begin{abstract}
Industrial machinery produce vibrations during its operation. Vibrations are transmitted to structure. However, an industrial structure is designed for these dynamic effects. But there are some dynamic effects which still to be considered. Those are, wind, earth quake and accidental blast loads. Though these loads are not frequent, but its occasional appearance will destroy the structure. An industry with thousands of labours, if gets these occasional dynamic effect, then it might result in much fatal. Therefore an industrial structure must be designed in such a way, that it resists the force created by these dynamic effects and dissipates in a better manner. This study is a numerical analysis of an industrial structure, subjected to wind, earthquake and blast load. The results are compared for severity, and the remedial measures shall be discussed. By adopting the remedial measures, the analysis shall be performed again and the effects will be compared with the earlier results of a normal structure. Drafting software Auto CAD is used for modelling the structure and SAP 2000 analysis software will be used for dynamic analysis. The purpose of this research project work is to study and understand the behavior of structure for dynamic loadings.
\end{abstract}

Keywords: Industrial structure, dynamic analysis, and blast load

\section{INTRODUCTION}

Large enclosures or industrial type buildings are very common in business parks, leisure and sports buildings. Their functionality and architectural quality are influenced by many factors, e.g. the development plan, the variety of usages and the desired quality of the building. For buildings of large enclosure, the economy of the structure plays an important role. For longer spans, the design is optimised in order to minimise the use of materials, costs and installation effort. Increasingly, buildings are designed to reduce energy costs and to achieve a high degree of sustainability. In most cases, an industrial building is not a single structure, but is extended by office and administration units or elements such as canopies. These additional elements can be designed in a way that they fit into the whole building design.

The main dimensions of an industrial building are usually determined from a combination of functional and design considerations. Its width is derived first from an owner's study of the space required to carry out the processing or storage operations. The designer then needs to consider whether this width can be provided economically by a single clear span, or whether multi-bay spans are feasible. Likewise the overall length is usually readily determined by the owner, but the designer should give thought to the optimum bay length. Some of the factors affecting the choice are:

- Foundation conditions and their ability to accept the column loads.

- Crane runway girder considerations

- Purlin and girt capacities

- Masonry bond dimensions.

- Tilt-up concrete panel size and available carnage.

\subsection{Need of Study}

Industries/ Factories are essential for nation's growth. It increases the productivity in a nation and decreases unemployment. A proper structure for industry is very essential for safe working, since it engages much employees. Normally an industrial building will experience dynamic loads by vibrations in machines. Along with this, accidental explosions may causing very high impact. Collapse of brick masonry structures during explosion also cause loss of human lives and hinder the continuity of manufacturing process. Existing construction guidelines are inadequate to resist against failure / collapse of brick masonry structures in the event of accidental explosions. An earthquake still danger for structures with more mass. Industrial building like looms or any fabrication units may be located in higher floor levels may experience huge inertial force in earthquake. Hence, framing appropriate construction guidelines for various explosion resistant performance, Earthquake and some dynamic effects are the most urgent need today.

\section{MODELLING AND ANALYSIS}

SAP2000 is a full-featured program that can be used for the simplest problems or the most complex projects. As normal software, the graphical user interface includes the main window, main title bar, display title bar, menu bar, toolbars, display windows, status bar, mouse pointer position coordinates and current units. Initialize the model from defaults with units option and drop-down list. When this option is selected, SAP will use the default program definitions. The default definitions are typical for the choice. 


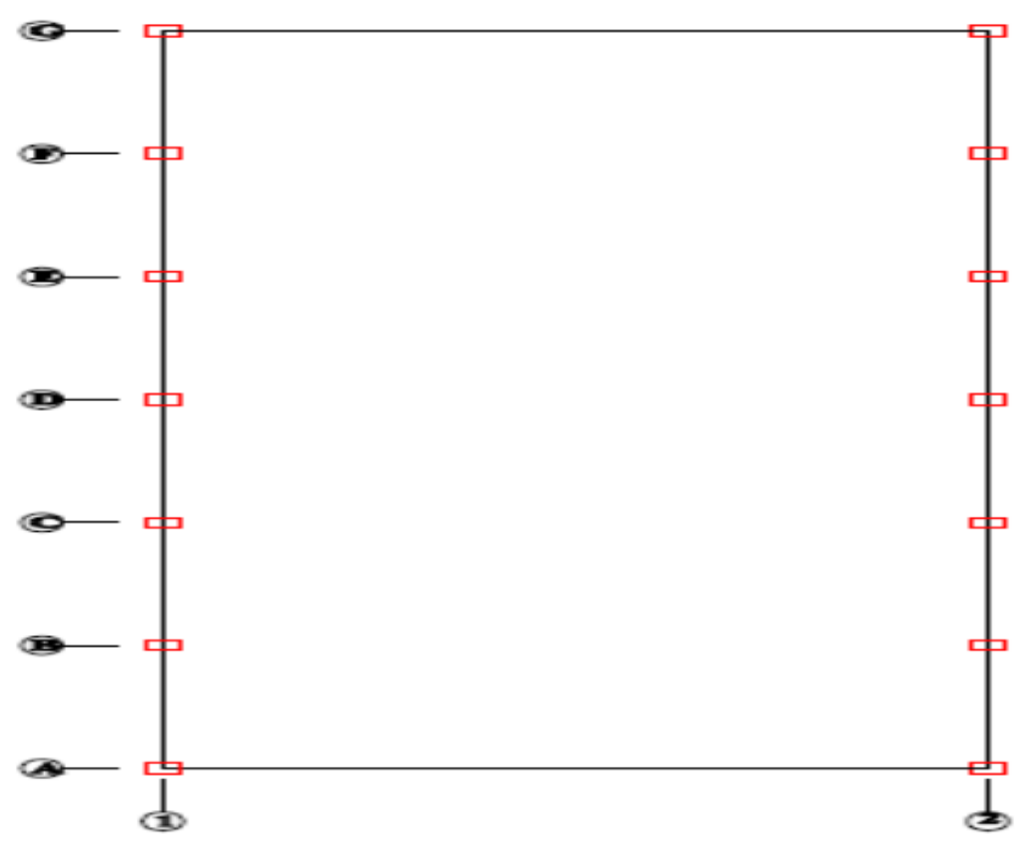

(a)

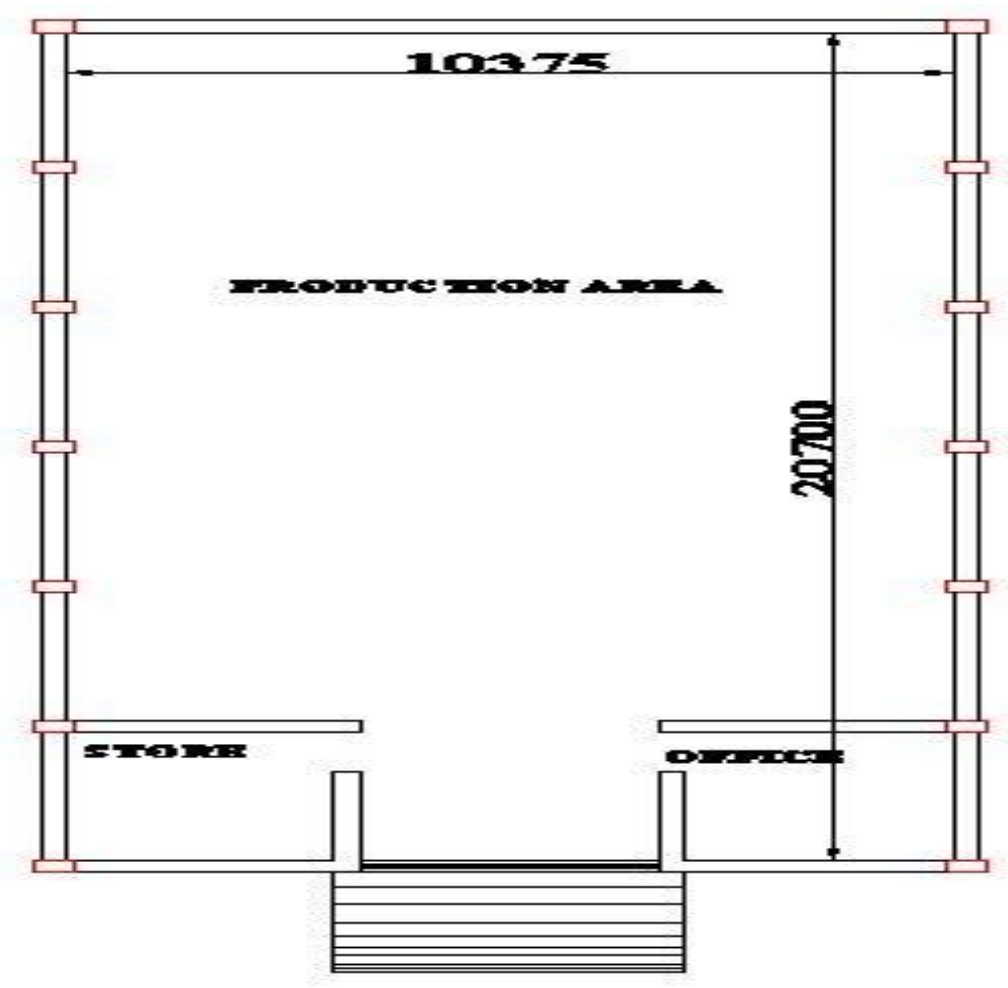




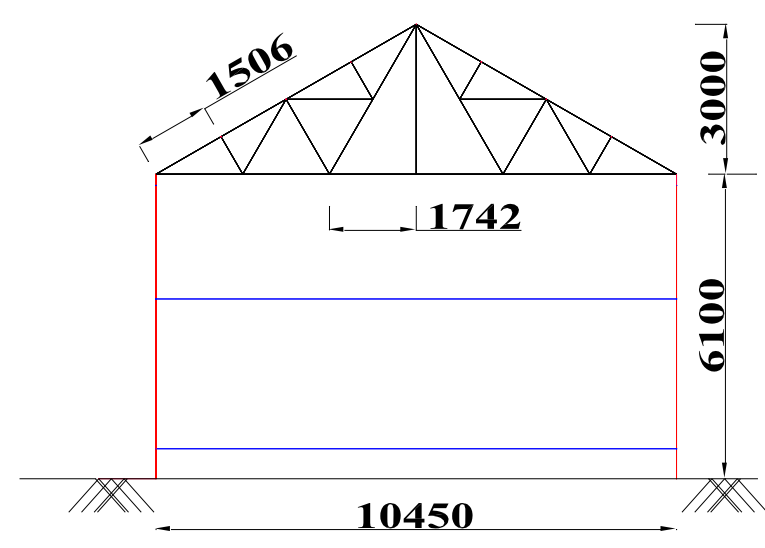

(c)

Chart 1 - a) Plan view, b) Column layout, c) Elevation

made in the select template area of the form. Where necessary, the default definitions can be modified using the commands on the define and assign menus. Our SAP model was drawn in Auto CAD 2014 and exported to SAP The line diagram of the Auto CAD is imported. While importing, units option to be taken much care. Auto CAD units much match the SAP units. Line diagram is modeled in metre units, so the import unit also will be set as metre units.

\subsection{Structure Details}

Column Size 300 X $450 \mathrm{~mm}$

Lintel Beam 300 X $450 \mathrm{~mm}$

Plinth Beam 300 X $450 \mathrm{~mm}$

Column Height $3.1 \mathrm{~m}$

Span of truss $-10.45 \mathrm{~m}$

Height of truss $-3 \mathrm{~m}$

Truss - ISA $100 \times 100 \times 6$

Purlin - ISA $60 \times 60 \times 6$

\subsection{Material:}

Columns and Beams: M25 Concrete

Poisson's ratio: 0.2

Roof truss: Steel

Steel

Yield strength: $250 \mathrm{MPa}$

Modulus of Elasticity: 210Mpa

Poisson's ratio: 0.3

\subsection{Loading}

DL - load from structural elements - as per IS 875 Part 1

LL - load from live load components - as per IS 875 Part 2

WL - As per IS 875 Part 3

EQ L - As per IS 1983 - 2002

Blast load

\subsubsection{Wind Load}

The wind loading is the most important factor that determines the design of tall buildings over 10 storeys, where storey height approximately lies between $2.7-3.0 \mathrm{~m}$. Buildings of up to 10 storeys, designed for gravity loading can accommodate wind loading without any additional steel for lateral system. Usually, buildings taller than 10 storeys would generally require additional steel for lateral system. This is due to the fact that wind loading on a tall building acts over a very large building surface, with greater intensity at the greater heights and with a larger moment arm about the base. Though our structure is not a high raise building, we are inducing wind load to have a study. Wind load is calculated as as IS 875 part 3

Design Wind Speed ( Vz )

$$
\mathrm{Vz}=\mathrm{Vb} * \mathrm{k}_{1} * \mathrm{k}_{2} * \mathrm{k}_{3}
$$

$\mathrm{k}_{1} 1.08$ important Structures

$\mathrm{k}_{2} 0.67$ Class $3+$ terrain 4

$\mathrm{k}_{3} 1$

$\mathrm{V}_{\mathrm{z}}=36.18$

$\mathrm{Pz}=0.6(\mathrm{Vz}) 2=0.7854 \mathrm{kN} / \mathrm{m}^{2}$

$\mathrm{F}=(\mathrm{Cpe}-\mathrm{Cp} 1) \mathrm{A} * \mathrm{Pz}=1.6415 \mathrm{kN} / \mathrm{m}^{2}$

\subsubsection{Earthquake Load Calculation (EQL)}

Seismic motion consists of horizontal and vertical ground motions, with the vertical motion usually having a much smaller magnitude. 


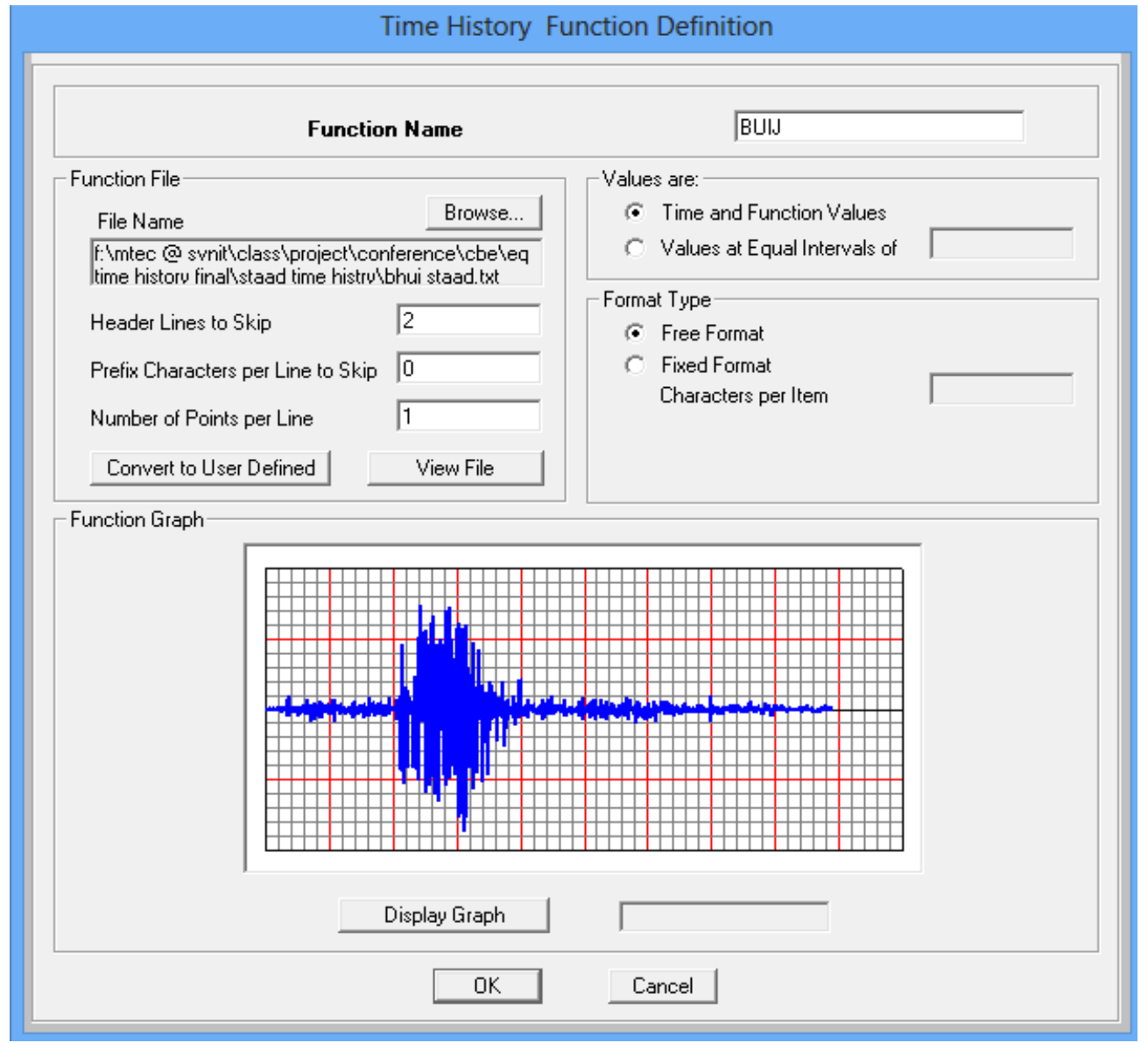

Chart 2 - Buij Time History

Further, factor of safety provided against gravity loads usually can accommodate additional forces due to vertical acceleration due to earthquakes. So, the horizontal motion of the ground causes the most significant effect on the structure by shaking the foundation back and forth. The mass of building resists this motion by setting up inertia forces throughout the structure. Earthquake load is induced as acceleration by Time - History method (Th). India's maximum earthquake Th Buij's acceleration is given as EQ acceleration in $\mathrm{X}$ and $\mathrm{Y}$ directions. Chart 2 shows the Th of Buij

\subsubsection{Blast Load Calculation (BL)}

Blast load gives high pressure to structural components. Its impact will vary with the distance from its origin and the structural elements. Our structure is symmentry and will have same effect when a blat occurs at its center. According to Young Seo Hwang [1] blast load is calculated by CONWEP program, which is taken as reference for our project. The units of measure of pressure and the distance is in psi and feet. As we are following SI units, the table must be converted to $\mathrm{N} / \mathrm{mm}^{2}$, metre and interpolated for our values. Structural elements will experience heavy load when the blast is any one side (worst condition). Therefore the blast loading shall be given at any corner A1/A2 or G1/G2(Chart 3) . In our analysis, blast load is induced in between G1 and G2. Since the blast load is applied at the center of G1and G2, the distance between the columns(Chart 3) and the interpolated values are tabulated in table 1 and 2.

Table 1 Impulse at Ground level

\begin{tabular}{|l|l|l|l|l|l|l|l|}
\hline $\begin{array}{l}\text { ID - } \\
\text { BLG }\end{array}$ & $\begin{array}{l}\text { G1/ } \\
\text { G2 }\end{array}$ & $\begin{array}{l}\text { F1/F } \\
\mathbf{2}\end{array}$ & $\begin{array}{l}\text { E1/E } \\
\mathbf{2}\end{array}$ & $\begin{array}{l}\text { D1/ } \\
\text { D2 }\end{array}$ & $\begin{array}{l}\text { C1/ } \\
\text { C2 }\end{array}$ & $\begin{array}{l}\text { B1/ } \\
\text { B2 }\end{array}$ & $\begin{array}{l}\text { A1/ } \\
\text { A2 }\end{array}$ \\
\hline $\begin{array}{l}\text { Dista } \\
\text { nce } \\
\text { in m }\end{array}$ & $\begin{array}{l}5.02 \\
4\end{array}$ & $\begin{array}{l}5.83 \\
6\end{array}$ & $\begin{array}{l}8.20 \\
8\end{array}$ & $\begin{array}{l}11.1 \\
8\end{array}$ & $\begin{array}{l}14.4 \\
0\end{array}$ & 17.7 & 21.1 \\
\hline $\begin{array}{l}\text { Load } \\
\text { in kN }\end{array}$ & $\begin{array}{l}930 . \\
9\end{array}$ & $\begin{array}{l}826 . \\
7\end{array}$ & $\begin{array}{l}454 . \\
4\end{array}$ & $\begin{array}{l}182 . \\
8\end{array}$ & $\begin{array}{l}138 . \\
6\end{array}$ & 92.8 & 85.0 \\
\hline $\begin{array}{l}\text { Time } \\
\text { in ms }\end{array}$ & $\begin{array}{l}8.33 \\
2\end{array}$ & $\begin{array}{l}10.0 \\
4\end{array}$ & $\begin{array}{l}16.9 \\
7\end{array}$ & $\begin{array}{l}16.4 \\
5\end{array}$ & $\begin{array}{l}17.6 \\
3\end{array}$ & 18.8 & 19.0 \\
\hline
\end{tabular}

Table 2 Impulse at Rooflevel

\begin{tabular}{|l|l|l|l|l|l|l|l|}
\hline $\begin{array}{l}\text { ID - } \\
\text { BLR }\end{array}$ & $\begin{array}{l}\text { G1/ } \\
\text { G2 }\end{array}$ & $\begin{array}{l}\text { F1/F } \\
\mathbf{2}\end{array}$ & $\begin{array}{l}\text { E1/E } \\
\mathbf{2}\end{array}$ & $\begin{array}{l}\text { D1/ } \\
\text { D2 }\end{array}$ & $\begin{array}{l}\text { C1/ } \\
\text { C2 }\end{array}$ & $\begin{array}{l}\text { B1/ } \\
\text { B2 }\end{array}$ & $\begin{array}{l}\text { A1/ } \\
\text { A2 }\end{array}$ \\
\hline $\begin{array}{l}\text { Dista } \\
\text { nce } \\
\text { in m }\end{array}$ & $\begin{array}{l}8.04 \\
7\end{array}$ & $\begin{array}{l}8.57 \\
7\end{array}$ & $\begin{array}{l}10.3 \\
3\end{array}$ & $\begin{array}{l}12.8 \\
3\end{array}$ & $\begin{array}{l}15.7 \\
1\end{array}$ & 18.8 & 22.0 \\
\hline $\begin{array}{l}\text { Load } \\
\text { in kN }\end{array}$ & $\begin{array}{l}335 . \\
682\end{array}$ & $\begin{array}{l}286 . \\
132\end{array}$ & $\begin{array}{l}205 . \\
093\end{array}$ & $\begin{array}{l}135 . \\
798\end{array}$ & $\begin{array}{l}104 . \\
464\end{array}$ & 70.8 & 76.4 \\
\hline $\begin{array}{l}\text { Time } \\
\text { in ms }\end{array}$ & $\begin{array}{l}16.3 \\
8\end{array}$ & $\begin{array}{l}16.4 \\
0\end{array}$ & $\begin{array}{l}16.9 \\
1\end{array}$ & $\begin{array}{l}17.9 \\
3\end{array}$ & $\begin{array}{l}19.0 \\
5\end{array}$ & 20.2 & 20.0 \\
\hline
\end{tabular}


Blast load is induced in each joint by triangular impulse obtained from the interpolation. For each joint, this impulse is programed as user defined time history. Time in $\mathrm{x}$ axes are taken as millisecond $(0.001 \mathrm{sec})$. In y axes, load in $\mathrm{kN}$ for each joint is feed. Chart 4 shows the triangular impulse defined for joint F1/F2 in ground level. This impulse incorporated in analysis as harmonic function in SAP 2000.

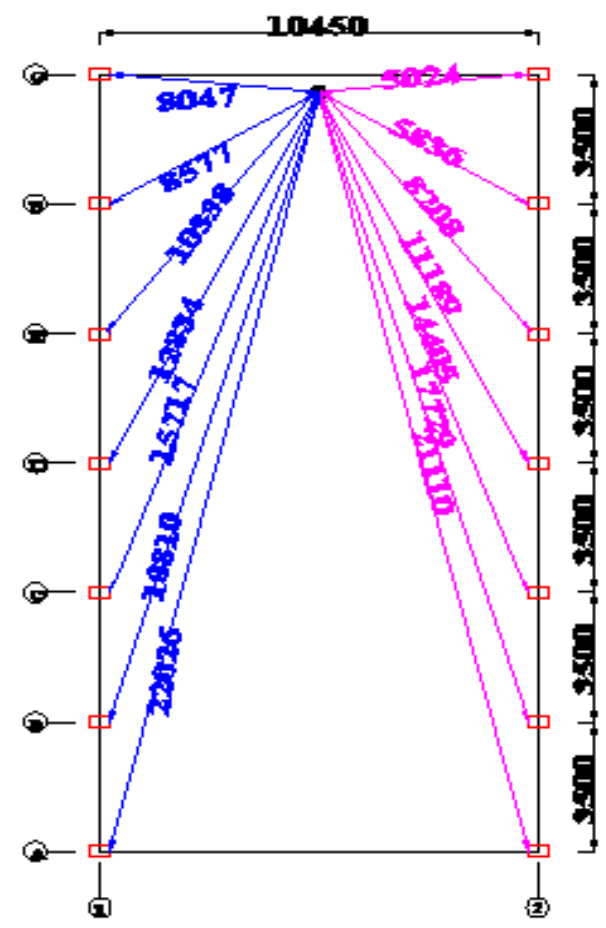

(a)

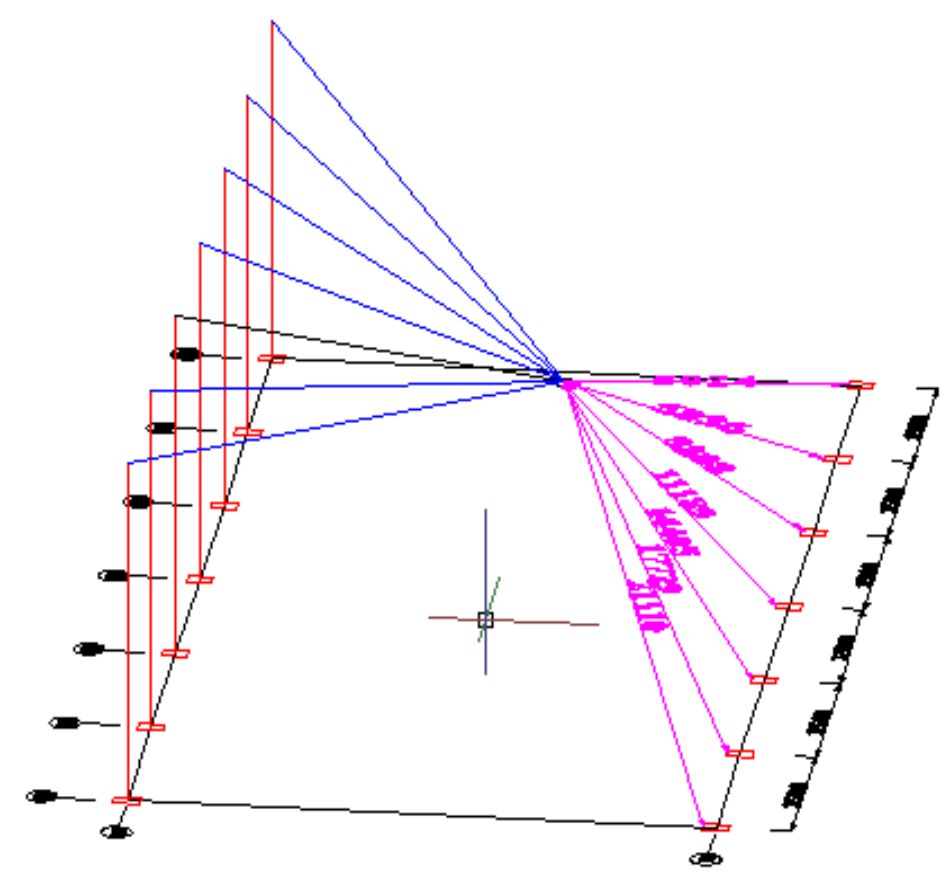

(b)

Chart 3a) Horizontal (Pink colour) distance to column base

Chart 3b) Inclined (blue colour) distance to column top 
For this mass source is defined in each joint by considering the volume of the material. At each joint the joint load is given as a function of harmonic function. Due to the pressure in both sides of the explosion, the column faces experiences positive directional pressure and negative directional pressure. Therefore the joint load coefficient in the grid 1 is taken as $-\mathrm{X}$ and grid 2 is taken as $+X$. Decay of pressure is assumed as 5 seconds. So the triangular function ends at 5 seconds.

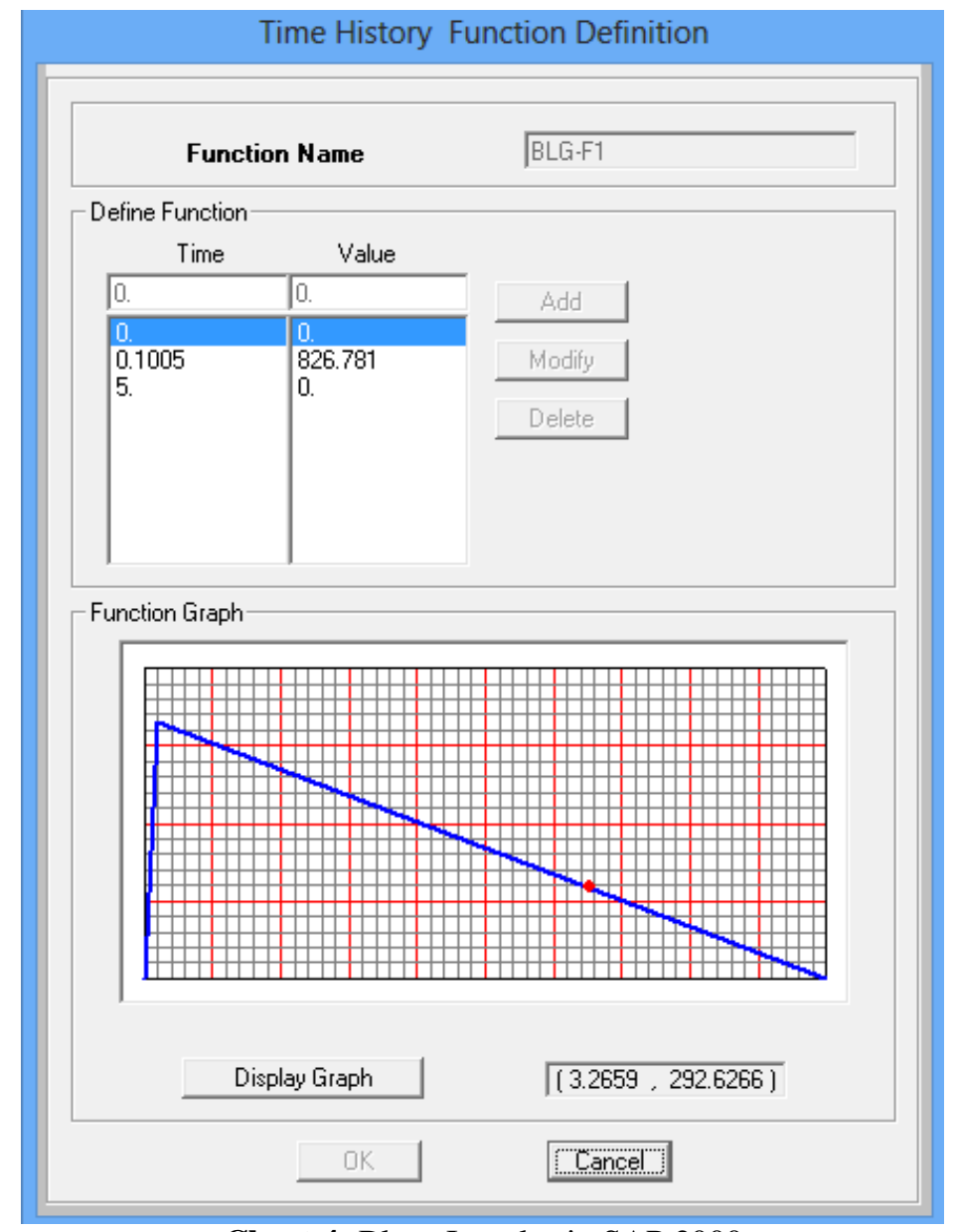

Chart 4- Blast Impulse in SAP 2000

\section{RESULTS AND DISCUSSIONS}

Results obtained was tabulated for load combinations and blast load. Maximum displacement and stresses are very essential to know the service of a structure. Therefore the maximum stresses in a critical element and the maximum Displacement of a critical joint in all load cases and blast load were studied and discussed.

\subsection{Joint Displacement}

\subsubsection{Results of Joint Displacement}

Maximum displacement is seen in joint 26 for load combinations. Chart 4 shows the displacement of Joint 26 for various load combinations. Negative sign (minimum) indicates the maximum displacement in opposite side. In the case of blast load, maximum displacement in horizontal plane is founded as $8185.74 \mathrm{~mm}$ in the same joint 26 . In vertical plane, maximum displacement is observed as $11527.01 \mathrm{~mm}$ in joint 62. 


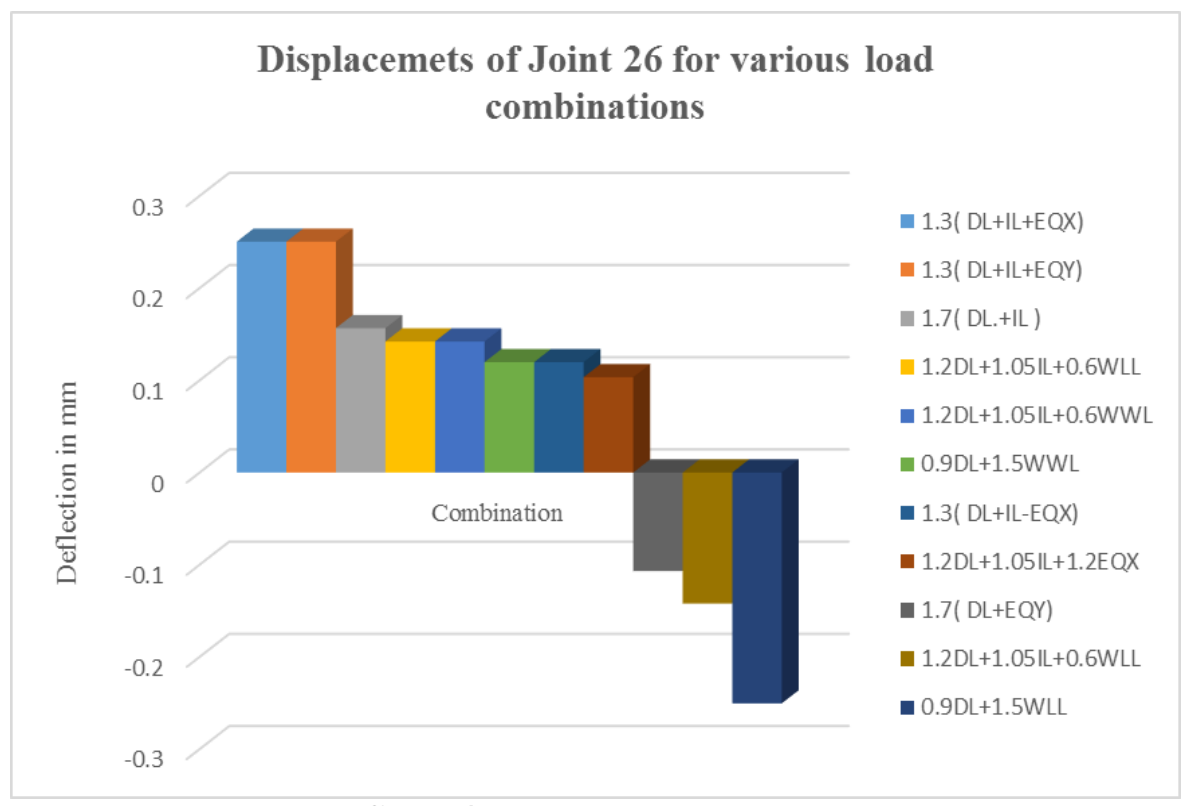

Chart 4 Displacement of Joint 26

\subsubsection{Discussion on Joint Displacement}

All joints at roof level experiences more displacement, which is evidenced by table 4.2. Combination of dead load, live load and earthquake load in $\mathrm{x}$ axes with a coefficient 1.3 induces much joint displacement. When the joint at roof level is compared with an inverted pendulum, this structural action can be easily understood. In an inverted pendulum, when the force is applied, the mass starts to oscillate. In this case, force is applied at the base as support movement (earth quake load) and the inertial action of mass induces the displacement. Since all the displacements in load combination are within a $\mathrm{mm}$, it can be said that, the structure is safe against live, wind and earthquake loads.

While seeing the blast load, the displacements are much greater like $11 \mathrm{~m}$. This indicates that, due to explosion, the roof is lifted upto an height of $11 \mathrm{~m}$. To overcome this, our structure must be modified by some special arrangements.

\subsection{Element Stresses}

\subsubsection{Results of Element Stresses}

Our structural elements are classified as beams, columns and roof truss. Since beams and columns experience axial load with moment, we have to check the principal stresses which is induced by some specific load combinations. Table shows 3 the maximum principal stresses.

\subsubsection{Discussion on Element Stresses}

In all load combinations the stresses are founded to be very less, when compared with blast load. Therefore load combinations are neglected. Maximum blast load stress occurs in frame element 263, which is a purlin (ISA $60 \times 60$ $x$ 6). Since this is the least section we provided in our design it failed first. Looking into the frame elements, columns 8, 9 (corner columns - near blast point) experiences much stresses. The stress value is $861302.550 \mathrm{~N} / \mathrm{mm}^{2}$.
Table-3: Element Stresses - Frames

\begin{tabular}{|c|c|c|c|}
\hline Frame & OutputCase & S11 & \\
\hline Text & Text & $\mathrm{KN} / \mathrm{mm}^{2}$ & $\mathrm{~N} / \mathrm{mm}^{2}$ \\
\hline 15 & 1.7( DL.+IL ) & 0.001333 & 1.333 \\
\hline 21 & 1.7( DL.+IL ) & 0.001333 & 1.333 \\
\hline 22 & 1.7( DL.+IL ) & 0.001333 & 1.333 \\
\hline 28 & 1.7( DL.+IL ) & 0.001332 & 1.332 \\
\hline 32 & $\begin{array}{l}1.7( \\
\text { DL+EQX) }\end{array}$ & -0.000056 & -0.056 \\
\hline 263 & BLAST & 11548872 & 11548871980 \\
\hline 258 & BLAST & 11508498.1 & 11508498140 \\
\hline 262 & BLAST & 11499838.6 & 11499838570 \\
\hline 261 & BLAST & 11495640 & 11495640010 \\
\hline 260 & BLAST & 11494992.8 & 11494992780 \\
\hline 259 & BLAST & 11491732.4 & 11491732370 \\
\hline 9 & BLAST & 861.30255 & 861302.550 \\
\hline 1 & BLAST & 740.45981 & 740459.810 \\
\hline 8 & BLAST & 861.30255 & 861302.550 \\
\hline 2 & BLAST & 740.45981 & 740459.810 \\
\hline
\end{tabular}

\subsection{Modal Analysis}

\subsubsection{Results of Modal Analysis}

The evolution of the natural time vibration periods of the building structure is quite important in the dynamic analysis of structure. A modal analysis calculates the frequency modes or natural frequencies of a given system, but not necessarily its full-time history response to a given input. The natural frequency of a system is dependent only on the stiffness of the structure and the mass which participates with the structure (including self-weight). It is useful to know the modal frequencies of a structure as it allows us to ensure that the frequency of any applied periodic loading will not coincide with a modal frequency and hence cause resonance, which leads to large oscillations. 


\subsubsection{Discussion on Element Stresses}

Table-4: Modal periods \& frequencies of load combinations

\begin{tabular}{|l|l|l|l|}
\hline OutputCase & StepNum & Period & Frequency \\
\hline Text & Unitless & Sec & Cyc/sec \\
\hline MODAL & 1 & 0.29674 & 3.37 \\
\hline MODAL & 2 & 0.165836 & 6.03 \\
\hline MODAL & 3 & 0.068389 & 14.622 \\
\hline MODAL & 4 & 0.067036 & 14.917 \\
\hline
\end{tabular}

Table-5: Modal periods \& frequencies of blast load

\begin{tabular}{|l|l|l|l|}
\hline OutputCase & StepNum & Period & Frequency \\
\hline Text & Unitless & Sec & Cyc/sec \\
\hline MODAL & 1 & 0.24871 & 4.0207 \\
\hline MODAL & 2 & 0.16779 & 5.9599 \\
\hline MODAL & 3 & 0.06777 & 14.755 \\
\hline MODAL & 4 & 0.06644 & 15.051 \\
\hline
\end{tabular}

From table 4 and 5, we shall observe that, the time period and frequencies of all modes are nearly equal. Since the Mode shapes are the function of mass of the structure, the frequency and time period are nearly same in load combinations and blast loading.

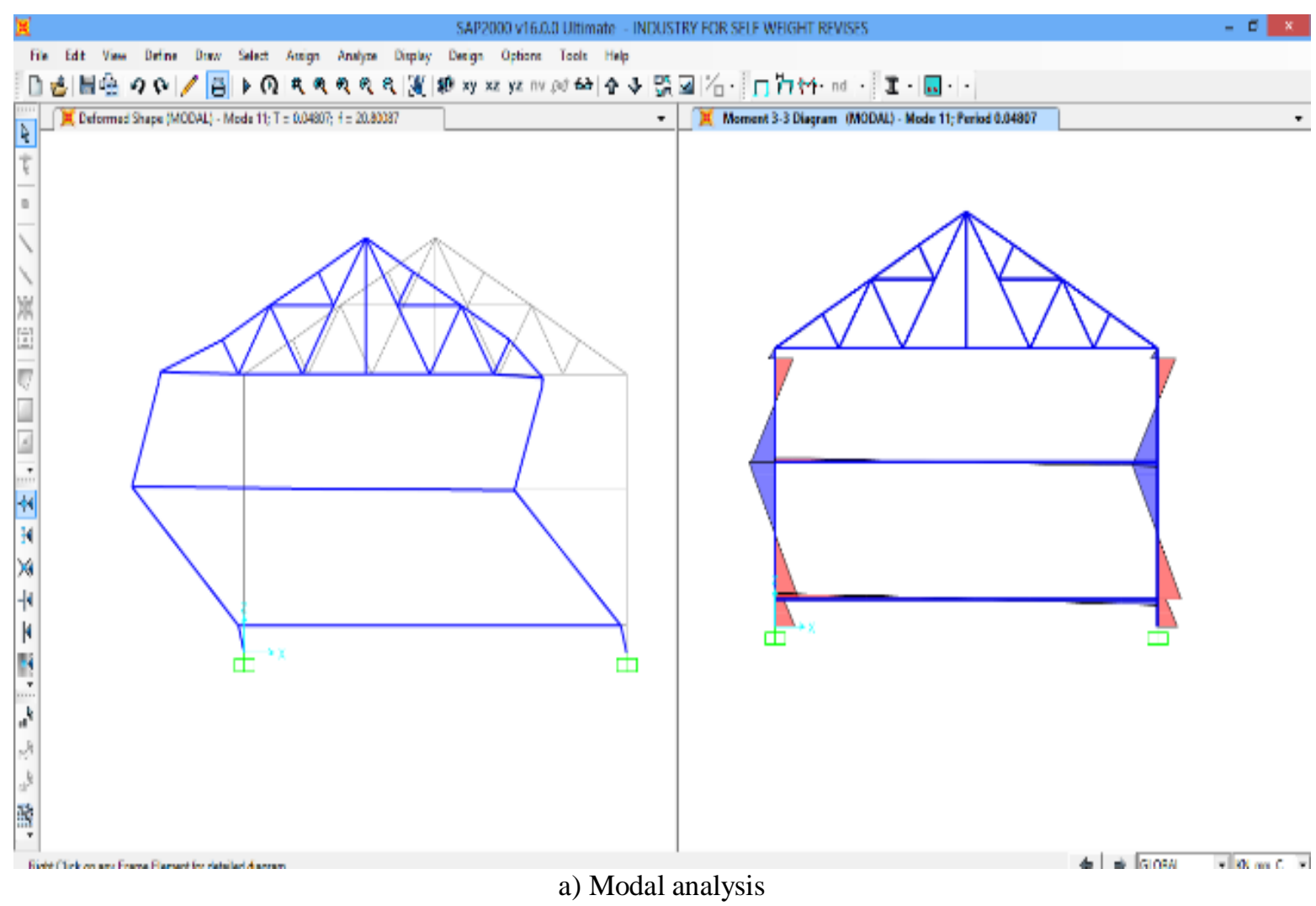




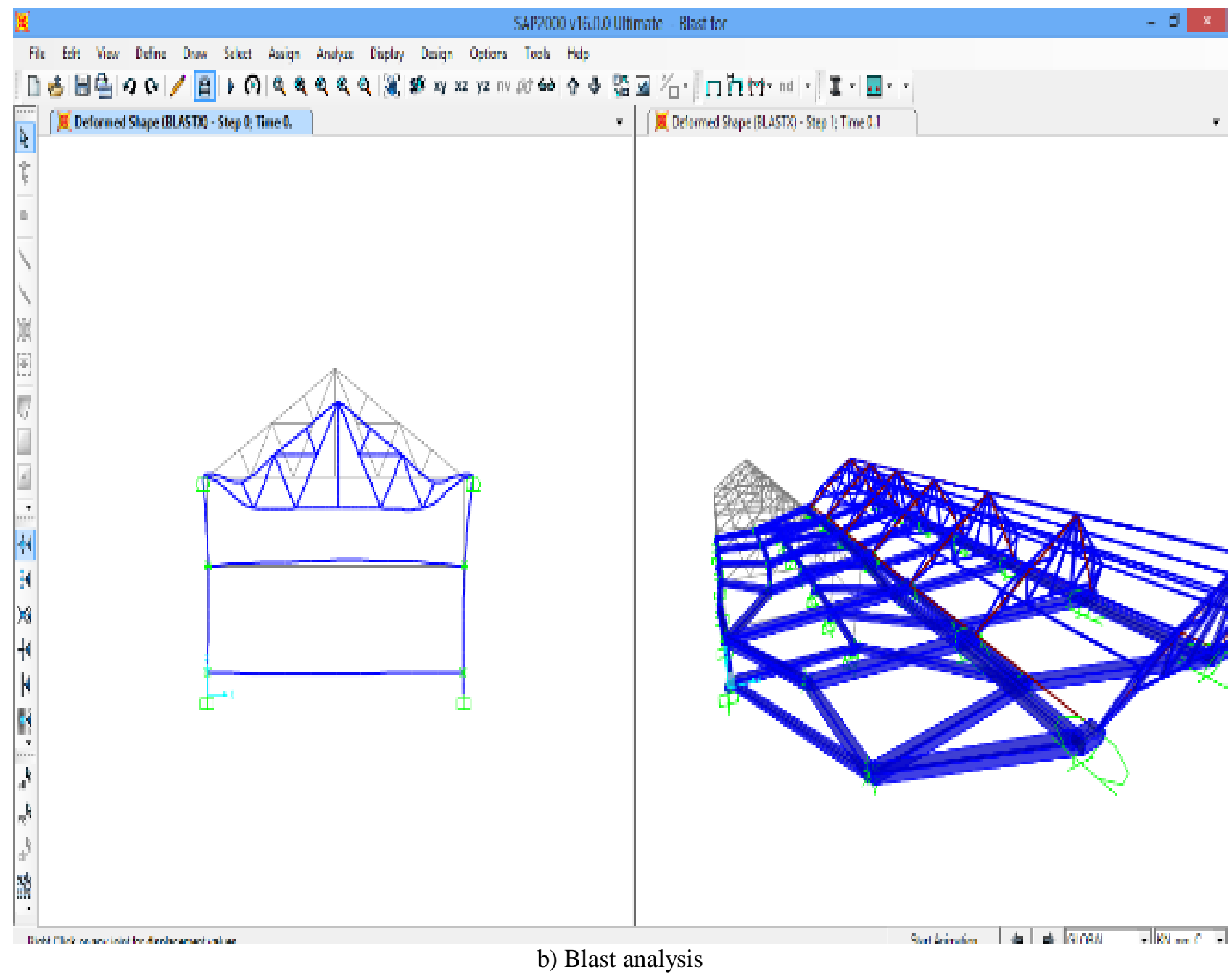

Chart 5 Deflection and bending moments of frame

\section{CONCLUSION}

To absorbed the blast load, the structural components must have very huge sections. This may increase the cost of the structure. An explosion in the open space will have less loss. Therefore by giving way to dissipate the blast energy, our structure will be safe. When opening are provided in wall and in roof, this can be achieved. Purlin failure is a local failure. So it is allowed to fail, but the main truss and the RC frame element if fails, it will lead to global failure. There is no chance that blast load will reduce. Therefore the only way to reduce the stress are to provide large surface area to face the blast pressure. This can be achieved by providing shear walls. Along with existing columns, the structure shall be modified with shear walls.

\section{SCOPE}

This research will be further continued by modifying the structure for the effects observed in this paper

\section{REFERENCES}

[1]. Young Seo Hwang “ Three Dimensional responses of a steel structure under blast loads" Dissertation, University of South California, Dec 2010.

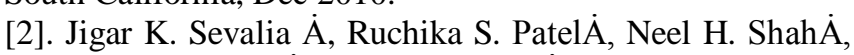
Akshay S. Agrawal $\dot{A}$ and Neha Modi $\dot{A}$ "Behavior Study of Industrial Building under Dynamic Load" International Journal of Current Engineering and Technology, P-ISSN $2347-51612014$

[3]. Sekar. T, S.N. Ramaswamy and NVN. Nampoothiri, "Studies on strengthening of brick masonry structures in fireworks industries against Accidental explosions", Asian Journal of Civil Engineering, Vol.13, No.6, 743-752 December 2012

[4]. B.M. Luccioni a,b, R.D. Ambrosini a,c, R.F. Danesi a,d "Analysis of building collapse under blast loads" Engineering Structures 26, 63-71 (2004)

[5]. Ruwan Jayasooriya, David P. Thambiratnam, Nimal J. Perera, Vladis Kosse "Blast and residual capacity analysis of reinforced concrete framed buildings" Engineering Structures 33, 3483-3495(2011). 
[6]. S.N.Ramaswamy and A.M.Arunmohan" Static and Dynamic analysis of fireworks industrial buildings under impulsive loading" : IJREAT International Journal of Research in Engineering \& Advanced Technology, Volume 1, Issue 1, March, 2013.

\section{BIOGRAPHIES}

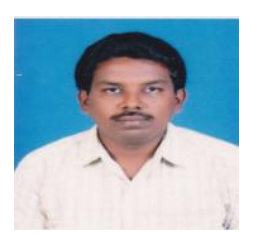

Mr.S.Ramesh,is an M.Tech Student at Prist University, Kumbakonam Campus and his field of interest is in structural analysis

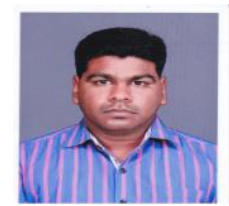

Mr. V. Vinoth Kumar, is an Asst. Professor, in Prist University, Kumbakonam Campus and his field of of interest is in structural analysis, concrete technology. 